angiomatosis need to be differentiated from pulmonary capillary haemangiomatois, seen in older children and adults. ${ }^{78}$ The latter is characterised by proliferation of capillary sized channels that infiltrate the lung interstitium and the walls of vessels and airways and leads to death from progressive pulmonary hypertension. Although the exact cause of these pulmonary vascular disorders is not clear, it has been suggested that they may represent an angiogenic disease-that is, lesions arising from non-neoplastic microvascular proliferation. ${ }^{679}$ The concept of angiogenic disease is based on the discovery and characterisation of several angiogenic polypeptides that can stimulate or inhibit capillary growth and differentiation. $^{9}$

Several therapeutic strategies have been attempted in diffuse haemangiomatosis. Although corticosteroids have been reported to shrink haemangiomas, ${ }^{10}$ this approach was unsuccessful in our patient, as in the cases of pulmonary haemangiomatosis described by others. ${ }^{1511}$ Radiotherapy may also cause regression of haemangiomas, ${ }^{12}$ but this approach was not considered feasible in our patient in view of severe restrictive lung disease. Similarly, diffuse pleural lesions precluded lung transplantation as a therapeutic option. A trial of cyclophosphamide treatment was embarked on, in view of a previous report ${ }^{13}$ attesting to its effectiveness in disseminated life threatening vascular tumours. Unfortunately, this approach was unsuccessful, possibly because the beneficial effects of cyclophosphamide in these circumstances do not materialise for several weeks and repeated courses of cyclophosphamide may be necessary. ${ }^{13}$ In recent reports a therapeutic response to interferon, an antiproliferative agent, was obtained in three children with pulmonary haemangiomatosis. ${ }^{614}$
Whether more patients with pulmonary haemangiomatosis will benefit from such treatment remains to be seen.

In summary, diffuse pulmonary angiomatosis is a rare clinical entity with an extremely poor prognosis. The possibility of this condition should be considered in a child with diffuse interstitial lung disease associated with increasing bloody pleural effusions.

We thank J Chay for secretarial assistance.

1 Goorwitch J, Madoff F. Capillary hemangioma of the lung. Dis Chest 1955;28:98-103.

2 Burman D, Mansell PWA, Warin RP. Miliary haemangiomata in the newborn. Arch Dis Child 1967;42:193-7.

3 Holden KR, Alexander F. Diffuse neonatal hemangiomatosis. Pediatrics 1970;46:411-21.

4 Koblenzer PJ, Bukowski MJ. Angiomatosis (hamartomatous hemlymphangiomatosis): report of a case with diffuse involvement. Pediatrics 1961;28:61-76.

5 Rowen M, Thompson JR, Williamson RA, Wood BJ. Diffuse pulmonary hemangiomatosis. Radiology 1978;127: 445-51.

6 White CW, Sondheimer EM, Crouch EC, Wilson H, Fan LL. Treatment of pulmonary hemangiomatosis with recombinant interferon alfa-2a. $N$ Engl $J$ Med 1989;320:1197-200.

7 Langleben D, Heneghan JM, Batten AP, et al Familial pulmonary capillary hemangiomatosis resulting in pulmonary primary hypertension. Ann Intern Med 1988;109:106-9.

8 Tron V, Magee F, Wright JL, Colby T, Churg A. Pulmonary capillary hemangiomatosis. Human Pathol 1986;17:1144-9.

9 Folkman J. Successful treatment of an angiogenic disease. $N$ Engl J Med 1989;320:1211-2.

10 Fost NC, Esterly NB. Successful treatment of juvenile hemangiomas with prednisone. J Pediatr 1968;73:351-7.

11 Hurwitz CH, Greenberg SH, Song CH, Gans SL. Hemangiomatosis of the pleura with hemorrhage and disseminated intravascular coagulation. J Pediatr Surg 1982;17: 73-5.

12 Kasabach HH, Merritt KK. Capillary hemangioma with extensive purpura. Am J Dis Child 1940;59:1063-70.

13 Hurwitz CH, Alkalay AL, Sloninsky L, Kallus M, Pomerance JJ. Cyclophosphamide therapy in lifethreatening vascular tumors. J Pediatr 1986;109:360-3.

14 White CW, Wolf SJ, Korones DN, Sondheimer HM, Tosi $\mathrm{MF}, \mathrm{Yu} \mathrm{A}$. Treatment of childhood angiomatous diseases with recombinant interferon alfa-2a. J Pediatr with recombinan

\section{Achilles tendon rupture: an underrated complication of corticosteroid treatment}

\author{
D M Newnham, J G Douglas, J S Legge, \\ J A R Friend
}

\begin{abstract}
Ten patients attending outpatient clinics who were taking oral corticosteroids ruptured their Achilles tendon in the course of 12 years. It is suggested that Achilles tendon rupture is a complication of corticosteroid treatment.
\end{abstract}

Oral corticosteroid treatment has many side

effects but Achilles tendon rupture is not widely recognised as one of them. Several patients with chronic airflow obstruction attending our hospital clinics were noted to have non-traumatic Achilles tendon ruptures while having long term oral corticosteroid treatment. We have reviewed our clinic population and found that during 12 years 10 patients had an Achilles tendon rupture related to steroid treatment.

\section{Details of the patients}

Details of the 10 patients and their episodes of tendon rupture are given in the table. Their mean age was 68.5 years and in every case the rupture occurred while they were walking on level ground. Rupture was diagnosed in five patients immediately after the sudden onset of pain in the Achilles tendon with local tenderness, swelling, and a palpable discontinuity that was sometimes visible. Extensive subcutaneous bruising developed around the ankle and extended over the dorsum of the foot within hours. The remaining patients presented some weeks after the onset of

Thoracic Medicine
Unit, Aberdeen Royal
Infirmary, Aberdeen
AB9 2ZB
D M Newnham
J G Douglas
J S Legge
J A R Friend
Reprint requests to:
Dr Friend
Accepted 18 July 1990


Details of the patients taking corticosteroids with spontaneous rupture of the Achilles tendon

\begin{tabular}{|c|c|c|c|c|c|c|}
\hline Patient No & $\operatorname{Sex}$ & $\begin{array}{l}\text { Age }(y) \\
\text { at rupture }\end{array}$ & $\begin{array}{l}\text { Steroid dose (mg) } \\
\text { (maintenance) }\end{array}$ & $\begin{array}{l}\text { Duration }(y) \text { of } \\
\text { steroid treatment } \\
\text { before rupture }\end{array}$ & $\begin{array}{l}\text { Type of } \\
\text { rupture }\end{array}$ & Treatment \\
\hline 1 & $\mathbf{F}$ & 69 & $5-10$ & 1 & $\mathbf{L}$ & Plaster \\
\hline 2 & $\mathbf{F}$ & 62 & $5-10$ & 3 & B & None \\
\hline 3 & $\mathbf{F}$ & 59 & $5-10$ & 3 & $L$ and $R$ ( 2 y apart) & None \\
\hline 4 & $\mathbf{M}$ & 86 & 10 & 6 & $\mathbf{R}$ & Plaster \\
\hline 5 & $\mathbf{M}$ & 80 & 10 & & B & Suture \\
\hline 6 & $\mathbf{M}$ & 70 & 5 & $3 / 12$ & $\mathbf{R}$ & None \\
\hline 7 & $\mathbf{F}$ & 62 & $5-10$ & 5 & B & None \\
\hline 8 & $\mathbf{M}$ & 60 & $5-10$ & 6 & $\mathbf{B}$ & None \\
\hline 9 & $\mathbf{F}$ & 75 & $5-10$ & 2 & $\mathbf{L}$ & Plaster \\
\hline 10 & $\mathbf{F}$ & 62 & 5 & 2 & $\bar{L}$ & Plaster \\
\hline
\end{tabular}

L-left unilateral; $\mathbf{R}$-right unilateral; B-bilateral.

similar symptoms. All patients had chronic airways obstruction and were taking maintenance oral prednisolone of 5-10 $\mathrm{mg}$ daily and all but one had been taking oral corticosteroids for at least one year. All were taking a beta $_{2}$ agonist and corticosteroid from a metered dose inhaler in addition, and some were receiving oral theophylline or bronchodilators from a domiciliary nebuliser.

\section{Discussion}

Traumatic rupture of the Achilles tendon is well recognised. Spontaneous rupture is less often reported but is known to occur in patients with rheumatoid arthritis ${ }^{1}$ and gout ${ }^{2}$ and in recpients of renal transplants. ${ }^{3}$ Reports of non-traumatic rupture of the Achilles tendon in patients having long term oral corticosteroid treatment are rare, especially bilateral simultaneous ruptures. Haines, reviewing all the reports in English, found only 10 cases of bilateral Achilles tendon rupture, each of which was thought to be related to corticosteroid treatment ${ }^{4}$; a further case was reported in a 77 year old man with giant cell arteritis after four months' corticosteroid treatment. ${ }^{5}$

During 198814 patients presented to the Aberdeen hospitals with traumatic rupture of the Achilles tendon, an estimated annual incidence of one in 35000 of the population. Their mean age ( 48.5 years) was considerably lower than that of our patients with nontraumatic rupture. About $10 \%$ of patients attending the Aberdeen chest clinics with chronic airways obstruction (around 500 patients) are receiving long term oral corticosteroid treatment. Our finding of 10 patients with Achilles tendon rupture over 12 years produces an estimated risk for patients taking corticosteroids who are attending our clinics of 1 in 600 a year. This supports our suggestion that long term oral corticosteroid treatment predisposes to an increased risk of non- traumatic rupture of the Achilles tendon. Achilles tendon rupture has not occurred in any of our patients with chronic airways obstruction not receiving oral corticosteroids.

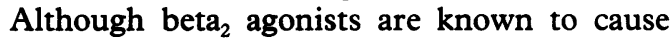
muscle cramps, none of the patients were taking beta ${ }_{2}$ agonists or unusually high inhaled doses, and none had complained of cramps immediately before tendon rupture.

The mechanism of rupture is forced dorsiflexion against a contracting calf and extending knee, and the diagnosis is confirmed by the presence of a bulging muscle belly in the proximal calf and a palpable gap in the Achilles tendon. Degenerative changes occur in the tendon from the third decade onward and these may be aggravated by corticosteroid treatment. This may explain why the patients taking oral steroids with non-traumatic Achilles tendon rupture are considerably older than those with traumatic ruptures. Only one of our patients was treated with open repair; the remainder of the ruptures healed by plaster immobilisation or by simple non-weight bearing after several weeks of disability.

Spontaneous Achilles tendon rupture in patients having long term corticosteroid treatment appears to be rather more common than has been suggested. We believe that this important and disabling complication of corticosteroid treatment merits greater recognition.

1 Rask MA. Achilles tendon rupture owing to rheumatoid disease. JAMA 1978;239:435-6.

2 Mahoney PG, James PD, Howell CV, Swannell AJ. Spontaneous rupture of the Achilles tendon in a patient with gout. Ann Rheum Dis 1981;40:416-8.

3 Pirson Y, Ghyser J, Squifflet JP, Alexander GPJ, De Strihoy CVY. Multiple spontaneous rupture of tendons in renal

4 Haines JF. Bilateral rupture of Achilles tendons in patients on steroid therapy. Ann Rheum Dis 1983;6:652-4.

5 Fest T, Dupond JL. Achilles tendon rupture. Lancet 1989;ii:918. 